\title{
Article
}

\section{"I Still Love Them and Wear Them"-Conflict Occurrence and Management in Wearer-Clothing Relationships}

\author{
Ana Neto ${ }^{1, *(1)}$ and João Ferreira ${ }^{2}(\mathbb{D}$ \\ 1 CIAUD, Research Centre for Architecture, Urbanism and Design, Lisbon School of Architecture, \\ Universidade de Lisboa, Rua Sá Nogueira, 1349-063 Lisboa, Portugal \\ 2 UNIDCOM/IADE-Unidade de Investigação em Design e Comunicação, Av. D. Carlos I, 4, \\ 1200-649 Lisboa, Portugal; joao.batalheiro@universidadeeuropeia.pt \\ * Correspondence: ana.neto@fa.ulisboa.pt
}

check for updates

Citation: Neto, A.; Ferreira, J. “I Still Love Them and Wear Them"-Conflict Occurrence and Management in Wearer-Clothing Relationships. Sustainability 2021, 13, 13054. https://doi.org/10.3390/su132313054

Academic Editors: Kirsi Niinimaki and Natalia Moreira

Received: 8 October 2021

Accepted: 21 November 2021

Published: 25 November 2021

Publisher's Note: MDPI stays neutral with regard to jurisdictional claims in published maps and institutional affiliations.

Copyright: (c) 2021 by the authors. Licensee MDPI, Basel, Switzerland. This article is an open access article distributed under the terms and conditions of the Creative Commons Attribution (CC BY) license (https:/ / creativecommons.org/licenses/by/ $4.0 /)$.

\begin{abstract}
The reasons why people use their clothes for longer are complex, but essential to understand how to promote longer clothing lifetimes. We conducted an online survey with open-ended questions, asking 170 female participants to write about one of their oldest garments still in use. When analysing our qualitative data, we found that many participants reported going through some mishaps with their item, a situation which is identified in existing literature as a reason for garment disposal. Following ongoing research which compares wearer-clothing relationships with human relationships, we analysed our qualitative data in the light of theory on interpersonal relationships to understand why conflict did not lead participants to dispose of their garments. The findings suggest that the way people manage conflict with their clothes is more critical for garment longevity than the conflict per se, which is bound to happen at some point in time. This paper presents different approaches to conflict in wearer-clothing relationships and illustrates them with testimonies from our survey. We discuss our findings through relevant literature and their implications to specific strategies for garment longevity.
\end{abstract}

Keywords: wearer-clothing relationships; conflict management; person-product attachment; clothing use; clothing longevity; sustainable fashion consumption

\section{Introduction}

This paper stems from a surprising research finding; surprising because it challenges our current knowledge on the reasons why people keep or discard clothes, and sheds new light on emerging strategies to enhance product lifetimes. In our survey on wearers' relationship with garments owned for a long time-and still in use-participants often revealed the occurrence of some mishaps, which have been identified in previous research as reasons for garment disposal [1].

The issue is important because current rates of resource throughput and waste in the fashion industry are causing irreversible damage to our environment-see [2] for an overview-which significantly undermines the present and future well-being of all. Producing durable clothing is paramount to enable slower consumption [3], yet durable features do not lead to a longer service-life of clothes if the wearers opt to dispose of them too soon [4]. Therefore, it is important to understand what makes people use their clothes for longer, which is the question driving the research project from which this paper derives. Wearer-clothing relationships are complex and very personal—see, for example [5,6]which makes it difficult to understand the role of design in promoting garment longevity beyond the production of durable garments. We developed a survey to explore our main question, and from our qualitative data emerged that expected reasons for disposal may not be reasons for disposal at all, which deserved a deeper analysis.

Our findings suggest that, as happens with interpersonal relationships, wearers are likely to face conflict in their relationship with their clothes at some point in time. Then 
why does conflict result in garment disposal in some cases and not others? As we will see, conflict management may be more influential for garment longevity than conflict itself.

In this paper, we call attention to the experience of conflict in wearer-clothing relationships and present a novel perspective to understand it. We examine different types of conflict in wearer-clothing relationships and how wearers manage them. Finally, we discuss how this significant component of wearer-clothing relationships might influence strategies for garment longevity.

\section{Our Relationship with Clothes}

In their study on clothing attachment, Niinimäki \& Armstrong found that the emotional connections that wearers form with their clothes foster "affection, and even love, towards the special item in a temporal context" [7] (p. 196), making the item irreplaceable for the wearer. Similarly, McIntyre [8] noted how "love" for clothes was frequent in clothing consumption diaries analysed in her study. In "Emotionally Durable Design", Chapman compares how we relate with objects to interpersonal relationships in a provocative illustration of current consumption habits: "During recent years, consumers have become serial honeymooners, and today subject-object relationships are less marriage, more one-night stand" [9] (p. 74). In her doctoral research, Beatriz Russo [10] identified similarities between love expressed in person-product relationships and interpersonal ones, which is consistent with Burcikova's argument that "our relationship to clothing needs to be an investment from both sides" [6] (p. 305). Further to this point, fashion activist Orsola de Castro argues that "when it comes to our clothes, we need to start looking for committed relationships: bonds that will last for a lifetime of wear (and tear)" [11] (p. 42).

Our previous work drew from Russo [10] to map how wearer-clothing relationships operate and evolve similarly to interpersonal relationships. We identified the five Levinger's relationship phases [12] that a wearer-garment relationship could go through attraction, build-up, continuity, deterioration, and ending. However, not all relationships undergo each phase; transition depends on how each wearer-garment interaction impacts the relationship variables of passion, intimacy, and commitment. Deterioration is a particular phase because it can be abrupt (leading to the end of the relationship) or gradual and non-linear.

In consumption research, the deterioration phase is known as divestment, a process people experience when separating from their belongings [13]. Similarly, divestment is not a straightforward process: each owner-product interaction is relevant and can contribute to accelerating, slowing down and even reversing the divestment [14]. Thus, despite the damage that conflict can inflict, wearers may still render the relationship salvageable.

\section{Methodology}

A questionnaire was developed as part of a doctoral project in which we adopted a grounded theory approach (see Muratovski [15] for a description of how to apply Grounded Theory in design research) to understand what makes people wear their clothes for longer. In this paper, we present an emergent insight that warranted deeper analysis, namely the occurrence of conflict in wearer-clothing relationships and the wearer's approach to conflict.

\subsection{Methodological Choices and Limitations}

This study is based on an extensive survey on long wearer-clothing relationships, in which participants were invited to write about one of their older garments still in use.

Following up on existing research on people's relation to clothes [7] as well as other products [10], we built a mostly qualitative open-ended questionnaire to delve into the complexities of these relationships. While open-ended questions depend on the willingness of participants to share their views, these frequently result in deep and detailed data.

To start identifying patterns and insights, we applied our qualitative questionnaire as an online survey (using Google Forms) which allowed us to gain a "wide-angle lens" on our 
topic, reach a geographically dispersed population, and obtain a sample size that is larger than usual for qualitative studies [16]. Overall, the resulting sample size made it possible for the insight presented in this paper to emerge. Despite the most obvious limitation of qualitative online surveys-that is, there is no opportunity for follow-up questions-our dataset is qualitatively rich, detailed, and varied which allowed us to analyse and elaborate on the implications of the insight; namely, to map the nuances on conflict occurrence and management (detailed in the results section of this paper).

Our questionnaire was aimed at adults. We chose to exclude children and teenagers because they can quickly outgrow their garments. Besides this, we did not impose any other recruitment criteria because wearer-clothing relationships are personal, which means we did not aim to distinguish behaviours of a certain demographic or socio-cultural subgroup. The study, therefore, did not depend on a sample that could be specifically representative of age, social class, or origin but instead aimed to gather a diversity of individuals in wearer-clothing relationships.

Due to time and resource constraints, convenience sampling (through the researcher's personal and social network) was used to recruit the wearers who were most readily available, willing, and able to participate. Our choice of medium and sampling method resulted in a sample residing mostly in the Global North and with higher education, to which we may associate a population with easy access to fast-fashion options (be it physical or online shops). To this end, and while convenience samples may lack transferability, our final sample provides a variety of experiences with which we believe many wearers in the Global North may relate to, as they refer to wearer-clothing relationships that are likely to endure because the wearers want so, and not due to lack of accessible alternatives.

\subsection{Sample}

The study we present in this paper analyses responses from women participants only, as they constituted more than $85 \%$ of submissions and a total of 170 valid responses. The vast majority of submissions came from western residents: 70 participants in Portugal, 42 in other European countries (14 of which in the UK), 55 participants in America (48 of which in the US), and 3 in other continents. The sample ranged in age from 19 to 80: 19-24 $(11 \%), 25-34(31 \%), 35-44(28 \%), 45-54(21 \%)$, and $\leqq 55(9 \%)$, most of whom had completed a college degree or higher $(92 \%)$.

Regarding the chosen clothes, $73 \%$ of the reported items were bought by the participant, $24 \%$ were received (mostly from family members, partners, or friends), and $3 \%$ cannot remember. Of all the clothes reported, $68 \%$ were considered a favourite item.

\subsection{Analysis}

As mentioned above, the questionnaire was extensive and contained numerous questions. For the purpose of this study, we focussed our analysis on the questions from which our initial insight emerged, namely on the qualities of the garments, changing use frequency, negative moments, damage, and relationship satisfaction [see questions 9, 11, 14, 15 and 17, in Appendix A].

Data analysis followed a grounded theory procedure [17], which underpins our overall research project. Accordingly, the procedure was the following:

(1) Coding: we applied open and descriptive coding (labels) to the data;

(2) Categorising: the second round of analysis was conducted to identify any clusters, patterns, or insights that emerged;

(3) Conceptualising: the emerging patterns were then compared with our previous findings in order to establish theoretical connections.

During the process of analysing, coding, and categorising the data, we constantly triangulated it with existing research (from the literature review) on clothing longevity and disposal and theory on interpersonal relationships. 


\section{Results}

\subsection{Conflict in Wearer-Clothing Relationships}

In interpersonal relationships, conflict occurs when the actions of one person interfere with those of another, and it can be infrequent or an ongoing behaviour [18]. We can also view conflict as "any interaction in which the rewards/costs ratios are unequal across partners" [18] (p. 1074). When two persons interact, there is an instant evaluation of the positive or negative value of that interplay [19]; the same applies when a person interacts with objects [10], like garments. In both cases, that evaluation influences further thoughts, feelings, and actions towards the other person or object, however unconscious the evaluation may be $[10,19]$.

The potential for conflict is intrinsic to any interpersonal interaction [18], and the same applies to the relation between wearers and clothes. In a study on how people-clothes relationships evolve, Valle-Noronha et al. recognise that these were "not always positive, but often rather shifting between pleasing and frictional events" [20] (p. 240).

Recognising the occurrence of adversity in $68 \%$ of wearer-clothing relationships from our survey, we questioned if specific garments were more prone to conflict than others.

However, every garment type shows more than half of the submissions reporting some conflict (Table 1). Categories such as "hoodies, sweatshirts" and "sleepwear, underwear" appear more prone to conflict, but they are also the least represented categories (and therefore, percentages are less illustrative). Overall, we did not identify significant differences in conflict prevalence across different garment types.

Table 1. Categorization by garment type and corresponding prevalence of conflict.

\begin{tabular}{ccc}
\hline Garment Type & $\begin{array}{c}\text { Items } \\
n\end{array}$ & $\begin{array}{c}\text { Conflict } \\
\%\end{array}$ \\
\hline Coats, Jackets, Blazers, Parkas & 42 & 61,9 \\
Sweaters, Jumpers, Cardigans & 31 & 67,7 \\
Jeans, Pants, Leggings, Skirts & 24 & 70,8 \\
Dresses, Jumpsuits, Rompers & 24 & 66,7 \\
Blouses, Shirts, Tunics & 18 & 61,1 \\
T-Shirts & 13 & 69,2 \\
Hoodies, Sweatshirts & 10 & 80 \\
Sleepwear, Underwear & 8 & 87,5 \\
\hline Total & 170 & 68 \\
\hline
\end{tabular}

Next, we analysed how time influenced the occurrence of conflict (Table 2).

Table 2. Wearer-clothing relationship longevity (broke down per age group) and prevalence of conflict.

\begin{tabular}{|c|c|c|c|c|c|c|c|}
\hline \multirow{2}{*}{$\begin{array}{l}\text { Relationship Longevity } \\
\text { In Years }\end{array}$} & \multicolumn{5}{|c|}{ Wearer's Age Group } & \multirow{2}{*}{$\begin{array}{c}\text { Total } \\
n\end{array}$} & \multirow{2}{*}{$\begin{array}{c}\text { Conflict } \\
\%\end{array}$} \\
\hline & $19-24$ & $25-34$ & $35-44$ & $45-54$ & $\leqq 55$ & & \\
\hline Up to 3 & 7 & 1 & 4 & - & 4 & 16 & 56 \\
\hline $4-6$ & 6 & 13 & 4 & 5 & 1 & 29 & 69 \\
\hline $7-9$ & 3 & 11 & 6 & 3 & - & 23 & 74 \\
\hline $10-12$ & 3 & 14 & 15 & 7 & 1 & 40 & 58 \\
\hline $13-15$ & - & 6 & 3 & 7 & 1 & 17 & 65 \\
\hline $16-18$ & - & 1 & 5 & 1 & 2 & 10 & 70 \\
\hline $19-21$ & - & 6 & 3 & 3 & 3 & 15 & 80 \\
\hline $22-24$ & - & 1 & 5 & 3 & - & 9 & 78 \\
\hline 25 and over & - & - & 3 & 6 & 3 & 12 & 83 \\
\hline Total $(n)$ & 19 & 53 & 48 & 35 & 15 & & \\
\hline Conflict (\%) & 79 & 68 & 71 & 63 & 60 & & \\
\hline
\end{tabular}


There was no minimum longevity required in our survey-only that the participants considered it one of the garments owned for the longest still in use. Thus, we received various answers, ranging from garments owned for two years to others owned for more than twenty-five years. As anticipated, clothes owned for longer revealed a higher percentage of conflict occurrence; however, we were surprised to find a significant percentage of more recent wearer-clothing relationships that underwent conflict as well. Nevertheless, in all the ranges of ownership duration, more than half of the submissions reported the occurrence of conflict.

Could age influence proneness to conflict? After grouping the reported relationships by the wearers' age, we find that conflict is likely to happen at every age, as more than half of participants in each age group reported going through mishaps with their chosen garment.

The consensus on interpersonal love relationships research suggests that relationships inescapably involve ups and downs [21,22], and conflict is natural and unavoidable [19]. Alford-Cooper conducted a study on long-term marriages in which one participant clearly explains the inevitability of conflict: "My mother once said to me, ... 'If you'd married so and so, you wouldn't have these problems.' And I told my mother that if I married somebody else, I'd have other problems. Problems are built in" [23] (p. 9). Further to this point, Gottman \& Gottman note that "relationships will work to the extent that one has selected a partner with a set of perpetual problems one can learn to live with" [19] (p. 18).

So, it is unsurprising that two-thirds of wearer-clothing relationships in our study experienced difficulty at some point (Table 1) and still thrived. Yet, why do these conflicts happen?

\subsection{Origins and Types of Conflict in Wearer-Clothing Relationships}

Theory on product attachment explains that user-product relationships can be influenced by changes in the owner, object, or context [24], and the origins of interpersonal conflict are attributed to differences in each partner and the ups and downs of life itself [22]. This is consistent with research on clothing use that identifies three factors for garment disposal: owner characteristics, garment characteristics, and situational factors [25]. Given the above, we categorised conflict occurrences by origin: the wearer, the garment, or the context, and noticed how previous research on motives for garment disposal as presented by Laitala \& Boks [1] matched our origins of conflict (Figure 1). We can see that fashion or style changes and taste-related unsuitability are issues originating in the wearer, whereas changes in garments are clearly a garment-related conflict; however, size and fit issues can originate either in garments or in wearers, functional shortcomings can be related to the garments or the context, and situational reasons for disposal are conflict situations originating either in the context or the wearer.

In the following section, we describe each type of conflict and illustrate it with testimonies from our study (identifying the participants' age, garment, and relationship longevity.)

\subsubsection{Conflict Origin in the Garment}

In their study on clothing use, Laitala \& Boks [1] identified that half the reasons for clothing disposal were changes in garments. Similarly, in our study, conflicts related to garments were the most frequently reported, mostly through the question on damage; in Table 3 we broke these incidents down into different types of mishaps: 


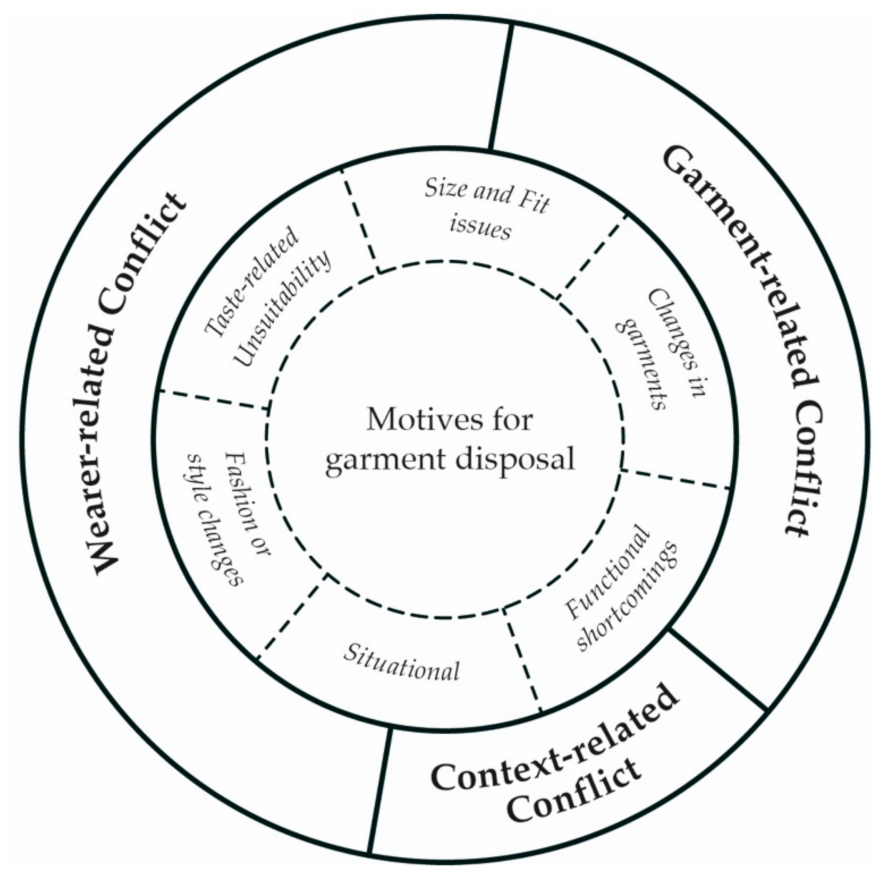

Figure 1. Motives for garment disposal [1] framed by conflict origins.

Table 3. Garment-related conflict by type, incidence, and related relationship rating.

\begin{tabular}{cccccc}
\hline $\begin{array}{c}\text { Garment-Related Conflict Found in } \\
\text { 81 Relationships }\end{array}$ & \multicolumn{2}{c}{ Relationship Rating (a) } \\
\hline Type & Occurrences & Very Unhappy & & Very Happy \\
\hline Changed garment: trims & 13 & - & - & 1 & 5 \\
Changed garment: holes & 11 & - & - & 7 & 7 \\
Changed garment: rips/tears & 28 & - & - & 3 & 13 \\
Changed garment: worn/faded & 25 & - & - & 1 & 14 \\
Changed garment: shape/size & 2 & - & - & 1 & 8 \\
Changed garment: stain & 13 & - & - & - & 1 \\
Garment original features & 5 & - & 4 & 4 \\
\hline
\end{tabular}

(a) Rating by the wearer on a scale of 1 to 5 in which $1=$ very unhappy and $5=$ very happy.

Conflict with trims refers to missing buttons, broken zippers, or any failure in garment hardware, which were often repaired/replaced:

Usually there can be some buttons loose, so I send to my grandma or to a store to fix it. I lost already one button. I felt sad because the buttons are super nice, clean, and gold colour, not easy to find similar ones that I could replace for all.-Charlotte (27), Beige Gabardine (6)

So far the dress only needed to have the zipper and the hook replaced. The zipper broke and the hook got rusty, which left a tiny permanent stain on the dress-Anne (41), Linen Dress (23)

Surprisingly, holes were frequently reported without having prompted action from the wearer, who kept wearing the item:

It's full of holes from wearing it for so long (...) Disappointed at first but now I don't care.-Susan (48), Navy Penn State Sweatshirt (24)

Hole in the elbows. [I was] Very sad until [I] decided to fix it.-Louisa (44), Cashmere Sweater (24) 
A frequent mishap was rips or tears. These are more noticeable, which may explain why many participants reported fixing them, unlike the few that mended holes. Still, some participants did not take any action at all:

The [hems] are damaged and never bothered to sew them.-Caroline (28), Yellow Hooded Jacket (10)

Worn or faded garments were often reported as well. When examining disposed garments, Laitala \& Boks [1] identified the point at which they were deemed worn enough to be discard varied across participants. In our study, some worn items were used less frequently, while other participants did not report any change in use frequency:

The sleeves have worn out. I felt sad, because I didn't want to buy a new one. I decided to keep wearing it anyway-Sophy (29), Red Sweatshirt (10)

Changes in shape or size of the garments were the least reported. Size incompatibility was more frequent due to changes in the wearer than the clothes. Yet, the wearers recognised these types of changes in the garments due to laundering:

The color changed and it completely lost its shape. I was sad but I understand what happened because it had a lot of wear and a lot of washing. On the other hand, it was a bit frustrating because it has some history (it belonged to my mother) and it is unlikely that I ever find a t-shirt this good.-Elinor (19), White T-shirt (5)

Participants also mentioned stains were a cause of negative feelings. While some wearers were able to remove the stains, others failed. Of the latter, some kept using the item, whereas for others it contributed to a downgrade in use:

It got a minor stain. I worked hard to get it out, but it's still slightly there if you look. I was annoyed it had happened because I love the jacket, but I still wear it anyway.-Jane (42), red trench coat (7)

I remember getting paint on it and being really bummed about it at the time as it was still when I wore it often and during the day-Emma (46), Lisa Simpson T-shirt (27)

Most conflict originating in garments was related to physical changes in the items. However, some wearers also had to overcome adversity related to original features, as is the case of Harriet and the sleeves of her jumper:

Sleeves too long [I] have to turn them up-Harriet (63), Jumper (3)

\subsubsection{Conflict Origin in the Wearer}

Conflicts related to wearers were often identified when we questioned participants on why use frequency changed over time, and were categorised on Table 4:

Table 4. Wearer-related conflict by type, incidence, and related relationship rating.

\begin{tabular}{|c|c|c|c|c|c|c|}
\hline \multicolumn{2}{|c|}{ Wearer-Related Conflict Found in 59 Relationships } & \multicolumn{5}{|c|}{ Relationship Rating (a) } \\
\hline Type & Occurrences & Very Unhappy & & & & Very Happy \\
\hline Changed wearer: body & 18 & - & - & 1 & 8 & 9 \\
\hline Changed wearer: taste & 25 & - & 1 & 7 & 14 & 3 \\
\hline Changed wearer: view & 4 & - & - & - & 3 & 1 \\
\hline Wardrobe flows & 21 & - & - & 4 & 13 & 4 \\
\hline
\end{tabular}

(a) Rating by the wearer on a scale of 1 to 5 in which $1=$ very unhappy and $5=$ very happy.

One of them is body changes, commonly related to weight fluctuations:

I can only wear it when I am thinner and exercising more.-Anne (41), Linen Dress (23)

Sometimes I put on some weight and do not like to see me in it as much.-Lizzie (48),

Checkered Shirt (25) 
Laitala \& Boks [1] report that changes in wearer's taste (fashion or style changes) amounted to $16 \%$ of reasons for garment disposal. In our study, this was the most common conflict type related with wearers:

For a couple of years I did not use it because it was a bit flashy but then I couldn't care less about that. So during summer I wear it a lot!-Cassandra (35), Denim Shorts (20)

I changed my style a bit in the middle. My outfits became more colorful, so I thought a grey skirt was a bit dull. Now that I'm back to dress in neutrals, I love it again.-Lydia (27), Grey Wool Pleated Midi-Skirt (10)

Both changes (body and taste) may explain why women keep clothes they no longer wear. Some women use or avoid clothes due to changes in their bodies on particular days $[26,27]$ or throughout extended periods. Interestingly, in our study, unsuitability between garment and the wearer's taste occasionally appeared at the start of the relationship, which could have resulted in early disposal, but instead led to a lasting relationship:

There was a time that was too big, but nowadays I like oversized.-Marianne (21), Knitted Sweater (11)

I have this really ugly shirt that used to belong to my mom back when she was young. I used to hate it but then got really into it because it is just comfortable and I wear it all the time because the design grew on me.-Sophia (24), Shirt (9)

In sporadic cases, participants reported dissatisfaction because their particular views changed. For example, one wearer felt her trench coat was less special while it was trendy in her country, and another participant felt her leggings were too expensive to use when she first got them. Maria's account is illustrative of how perception can affect the relationship — when asked about negative moments with her jeans, she shares:

Sometimes the jeans make me look short.-Maria (25), Jeans (6)

Wardrobe flows were identified as a conflict when participants recognised that other items interfered with their relationship with the chosen garment. Constantly engaging in new relationships with other clothes reduces the opportunity to engage regularly with items already owned, as new garments tend to be used more frequently than older ones [28] and "items used more frequently tend to sustain stronger relationships" [20] (p. 227). Several participants in our study reported a period in which the chosen garment was used less because "in the meantime I bought more training pants", "bought other dresses", "now I have lots of items to choose from". However, our study revealed that new garments were not irreversibly detrimental to the relationship with items already owned:

Sometimes I get a new one and this one takes a back seat, but it always comes back out-Augusta (41), Sweatshirt (10)

There was a time [when] new coats came in and I remembered them [more] often than the oldest parka. Eventually the parka came back at one of those days you feel "you have nothing to wear" and then you realize you do have and how well it fits on you.-Elisabeth (37), Suede Bege Parka (12)

While these relationships survived the acquisition of new items, research shows that wearers with larger wardrobes use their clothes less often than wearers with smaller wardrobes [29]. As a result, and despite using their clothes for longer, wearers with larger wardrobes are unlikely to know why some garments go out of use [29], which suggests that mindless management of wardrobe flows and volumes can damage wearer-clothing relationships.

\subsubsection{Conflict Origin in the Context}

Conflicts related to context were the least reported in our sample. These are mishaps produced by life itself for motives unrelated to the wearer or garment. In this category, we distinguished three types of conflict: changed places, changed jobs, and interpersonal (Table 5). 
Table 5. Context-related conflict by type, incidence and related relationship rating.

\begin{tabular}{cccccc}
\hline $\begin{array}{c}\text { Context-Related Conflict Found in } \\
\text { 19 Relationships }\end{array}$ & \multicolumn{2}{c}{ Relationship Rating (a) } \\
\hline Type & Occurrences & Very Unhappy & & Very Happy \\
\hline Changed place & 5 & - & - & - & 4 \\
Changed job & 7 & - & - & 1 & 3 \\
Interpersonal Relationships & 8 & - & - & 1 & 3 \\
\hline
\end{tabular}

(a) Rating by the wearer on a scale of 1 to 5 in which $1=$ very unhappy and $5=$ very happy.

Changing places is a "stress test" to many wearer-clothing relationships as it is frequently an occasion to purge the wardrobe. In our study, changing places usually led participants to wear their chosen garment less often. This happened when participants moved to different climates, to a new country, or moved out temporarily, e.g., to attend university:

I moved further south and was in a cold climate fewer days, so I didn't wear it as much as before I moved.-Fanny (37), Purple Sweater (20)

I left it at home when I came to study in college. - Caroline (28), Yellow Hooded Jacket (10)

Job changes were identifiable as a conflict source because they influenced the garment's frequency of use, either because it became the participant found it unsuitable or because the employer required different working attire:

My job changed. I used to wear it often when I was in the classroom. I have an office now and I am trying to wear a different style of clothes.-Lucy (46), Grey Romper (4)

I wore it a lot then I started working with children and it became impractical to wear so I wore it less.-Margaret (31), Teal Tulle Skirt (15)

Trying to keep wearing older garments, even beloved ones, in a context such as a change of jobs may be a challenge particularly difficult to overcome, for fashion has indeed the role to allow wearers to 'fit in' different social spheres [30] such as the professional one. Margaret's case is particular in that her new job now implied working with children, so the change in work attire followed practicality-more than appropriateness-as a result of interactions with other people (i.e., the children), which we also identify as a source of conflict in wearer-clothing relationships.

In this sense, what we label interpersonal conflict is wearer-clothing mishaps originating in interpersonal relationships; for example, caring for a toddler renders a deep cleavage impractical and uncomfortable [20]. In our study, examples include marital issues and family deaths:

My former husband was displeased that I spent money on myself, especially that I accessorized it with a new scarf. I was scared and stopped wearing it while he was home. For a long time I felt ice in the pit of my stomach when I saw it. But after my divorce it was somewhat like a badge of my freedom from abuse.-Frances (51), Navy Blue Summer Dress (8)

[my grandma's funeral] was the most special moment and the saddest, since from there on she wouldn't fix it, or be happy to see me with it.-Marianne (21), Knitted Sweater (11)

Additionally, interpersonal conflict may derive from other people's comments. A person may wear a particular garment more often after receiving compliments on it, or enjoy it less after hearing criticism:

[A negative moment was when] current partner said it looks granny but I ignore him.Rebecca (40), Blue Cardigan (16)

Different types of conflict affected several of the wearer-clothing relationships reported in our study. In the example below, Eliza's relationship with her jacket went through changes in context (moving abroad, mother's comment), garment (becoming shabby), and wearer (developing a preference for hoodies): 
I loved it when I first got it. A friend of mine liked it as well and we sometimes switched jackets, that made it even more special to me. I stopped wearing it when I went abroad for a year during school time, because I went to Malaysia and didn't really need a jacket. Also it got a bit shabby over time, so I felt embarrassed to wear it later on. (...) [a negative moment was] my mom telling me that it looks a little worn out. I felt a bit protective of it, but also a little embarrassed, I think. (...) I generally stopped wearing jackets so much and went for hoodies the last few years. Well, now [that] I spent so much time at home, I took it out of my wardrobe again and felt really comfortable wearing it again.-Eliza (24), Brown Sweat Jacket (10)

Interestingly, regardless of conflict type, a vast majority of wearers who reported mishaps also reported being happy or very happy with their relationship with the garment (Tables 3-5). Thus, the intriguing point is: how come these conflicts did not result in garment disposal? Or, conversely, how come these conflicts result in garment disposal for other people?

Theory on interpersonal relationships provides us with a clue: in romantic couples, it is known that some lay beliefs are harmful to relationship satisfaction [31]. For example, believing that disagreement is a sign that something is wrong results in unrealistic expectations that interfere with relationship fulfilment. Dissatisfaction may ensue, when in reality "conflict in itself is not a sign of deterioration" [22] (p. 80); it is natural and unavoidable.

Research on clothing use suggests that similar lay beliefs may influence wearers in their relationships with their clothes: for example, there is currently little expectation that goods should last [32], so any sign of garment deterioration triggers the deterioration of the relationship itself; another example is that cheap fashion is not worth mending [33], signalling that wearer-clothing relationships are not worthy of nurture and care. These beliefs result in minimal effort to keep clothes in use for longer.

As we found many participants were unaffected in their relationship satisfaction with their chosen garment in spite of adversity, we proceeded to analyse our data further to understand their behaviour towards conflict with their clothes.

\subsection{Dealing with Conflict in Wearer-Clothing Relationships}

We can look at limitations not as restrictions but as ways to stimulate alternative solutions, challenging ourselves to think of imperfections and faults as opportunities for improvement, rather than something to be discarded.-[11] (p. XVI)

In her book Loved Clothes Last, Castro identifies mending as a state of mind, a natural willingness to engage in repair when one puts one's mind to it [11]. Laitala \& Boks identified textile degradation as the crucial reason for garment disposal, but also recognised the engagement of several participants in practices of repair [1], which signals the intention to extend the relationship with the garments. In our study, the garment itself was one of the most frequently reported origins of conflict; however, this did not result in its disposal and did not seem to have a significant impact on relationship satisfaction. What brings about this outcome?

Given the unavoidable nature of conflict, the ability to deal with it and compromise is paramount to the longevity of long-term interpersonal relationships [23]. Can human behaviour in interpersonal conflict help us understand wearers' behaviour towards their clothes in the face of adversity?

Theorists on interpersonal relationships identify several strategies to deal with conflict, which can fall into three types depending on their outcomes: some are considered destructive, as they harm the relationship; some are constructive, as they improve the relationship; and others are ambiguous, as their consequences are more difficult to assess and depend on several factors [18].

In this section, we will analyse our data in light of these strategies. However, there are limits to the parallel between wearer-clothing and interpersonal relationships. Despite their ability to elicit actions, thoughts, and feelings in wearers, clothes do not have intentions or make decisions. As such, some conflict strategies-e.g., domination, where a person 
convinces another to choose their side of the issue-sit outside the scope of this comparison. Therefore, the strategies discussed here are the ones we can identify in wearer-clothing relationships (Table 6).

Table 6. Conflict strategies in wearer-clothing relationships.

\begin{tabular}{ccc}
\hline Destructive & Constructive & Ambiguous \\
\hline Criticism & Cooperation & Avoidance \\
Defensiveness & Compromise & Separation \\
\hline
\end{tabular}

Destructive strategies include, for example, defensiveness, which happens through blaming the partner or expecting unilateral change or action from the partner, all of which have a negative impact on relationship satisfaction [34]. Another strategy one might recognise is uncompromising criticism when, in the face of conflict, wearers resent the garment for a negative interaction or when the wearer deems the garment unworthy of effort to overcome the issue (e.g., the item is low quality, so not worth mending or using). In our data, we did not find signs of clearly destructive approaches as the examples above; instead, we found evidence of constructive and ambiguous strategies.

Constructive strategies have a positive effect and contribute to the growth and maintenance of the relationship, relational intimacy, and relationship satisfaction [34]. Our study reveals constructive approaches to conflict such as cooperation when wearers look after their garment (e.g., care routine) and strive to prolong use (e.g., through repair, alterations, restyling).

Despite some pilling, the jacket is made of a relatively good quality fabric, which has allowed it to keep some of its shape and initial looks. I have also been very careful with it by removing the pilling I can and only cleaning the outside with a slightly damp cloth (as it does not allow washing) and dry cleaning when needed. (...) The jacket initially had a golden chain stitched onto the shoulder seams, resembling shoulder boards. With the use and over the years, the stitching broke and the chains became increasingly loose. Eventually, some of it broke as it got stuck to shoulder bags and hair, so I decided to remove the chains. The jacket was in great condition and it was only this detail that was making it look ugly and sloppy. So I decided to remove the chains and the stitching altogether. In the end I liked the jacket even more, without this detail. It looked solemn and elegant.-Isabella (31), Black Winter Jacket (7)

But cooperation can also be found when the origin of conflict is the wearer:

I had gained weight and couldn't button the pants; I felt irritated and sad, and a little mad. My negative feelings were directed at myself and not the pants. I wore them unbuttoned with a tube top under my shirt to conceal that they were unbuttoned for several months until I could button them again and felt proud when that happened.-Esther (37), Widelegged Gray Slacks (10)

Another recognisable conflict approach is compromise. In interpersonal relationships, compromise is a positive approach and occurs when a person is prepared to accept less than originally intended in order to overcome a conflict. Compromise can also be a strategy where the solution is not ideal for either party. We can identify compromise in wearerclothing relationships when the second-best solution is used, for example, when the item is still used but not with the same frequency. This frequently happens with conflict originated in context:

When I had to work every day I barely wore it. During vacation or times off I wear it more often.-Nancy (36), Pants (11)

Compromise is a strategy that can also be associated with relegated items, that is, garments that were destined for everyday use and are now used only outside social contexts (e.g., loungewear or PJs) or for messy tasks such as painting or gardening: 
In the course of the years the colors have faded. Once it got a small stain nearly invisible but I am sorry about it. ( . . ) [It] was used outside first but already many years I wear it at home and in the garden.-Georgiana (61), Cotton Coat (31)

We can identify this strategy in previous research by Laitala \& Boks [1], who found that worn-out garments are not discarded when they are favourites, as they can be used outside of social occasions. Thus, while we can consider compromise as a positive approach to conflict (since it extends the use phase), there is the caveat that relegated items free daytime wear to be filled by new items. This situation is unlikely to be reversible:

I wore it often when I got it as oversized shirts were fashionable then, but over time as fashions changed I now wear it as a bedtime shirt/sleepwear as it's too big and too worn to be "fashionable" as daytime wear.-Emma (46), Lisa Simpson character T-shirt (27)

Moreover, one can look for a compromise to avoid the escalation of the [35]; however, in this case, we witness an accommodating behaviour that can contribute not to relationship satisfaction but to relationship deterioration. While some married couples stay unhappily married due to their ability to compromise [23], relationships with clothes do not hold that level of commitment and, consequently, do not elicit the same effort to maintain. Furthermore, even when something about the garment prevents the owner from discarding it, it is simple to move it to inactive storage or push the item to the far corners of the closet, giving way to newer items to be kept within reach.

Thirdly, we have conflict strategies that are ambiguous. These are not constructive or destructive, as they result in a non-confrontational approach which is difficult to associate with relationship satisfaction or conflict resolution [34]. Examples of such strategies are avoidance and separation.

We can identify avoidance when the wearer ignores the conflict, hoping it will pass over time or refuses to deal with conflict in due time. However, an overlooked hole may grow to the point where it cannot be ignored or effectively mended. Or staining a garment and neglecting to address the issue immediately may lead to disappointment when it comes out of the machine still stained.

Infrequent wear can signal a lack of interest in the garment or relate to an avoidance approach to potential conflict. On the other hand, some participants in our study refer to "infrequent wear" that results in the desire to prolong the life of the item:

I wear it rarely, have never washed it and do my best to keep it well stored and protected. (...) I wear it on occasions that will unlikely get it dirty.-Julia (30), Knitted Waistcoat (10)

In the last years, I have bought others to have in rotation, also because this jacket is starting to fall apart.-Bella (33), Winter Jacket (11)

Canary \& Cupach suggest that avoidance may reflect a perceived lack of ability to deal with conflict and an attempt to avoid the adverse effects of dealing with it [34]. However, Kayabol et al. argue that doing one's best to improve the relationship instead of avoiding conflict is better for those undergoing such efforts [36]. In this sense, care and maintenance could be more favourable for wearer-clothing relationships than infrequent use as a strategy to avoid conflict.

The Separation tactic happens when there is a temporary physical separation between both parts of the conflict with the intention to attempt reconciliation at a later moment. In wearer-clothing relationships, it is a strategy that can be identified when garments are stored away while not fitting the wearer's body, as happened with Alicia:

[a negative moment was] Putting it on when I was pregnant and already feeling uncomfortable in my body. It made me feel very unattractive and drew attention to my belly so I put it in a cupboard where I store stuff I don't use until recently, 10 [months] post partum, I raided that cupboard and put it back on.-Alicia (33), Oversize Jumper (6)

For participants reporting avoidance and separation, these were conflict approaches with seemingly positive effects as the relationship has been maintained. However, they 
could have detrimental effects. For example, garments infrequently used due to avoidance or separation can decrease intimacy and commitment. In their study on product divestment, Encino-Muñoz et al. identified irregular use as a point when items may be on the brim of physical divestment [14]. This is the moment when divestment can be prevented because use can contribute to the item's value [14]. Nonetheless, the fragility of the relationship at this point may precipitate an early end by lack of action to deal with conflict.

As previously noted, we found several wearer-clothing relationships presenting more than one type of conflict. Similarly, we could also find combinations of different approaches to conflict:

I was at the store and the wind blew and lifted the dress and people saw my underwear. I felt disappointed that I was starting to grow out of it, it was becoming small and the material was becoming [thinner], but I decided to start wearing shorts under it and not wear it on windy days or shopping.-Catherine (27), Mini Skater Dress (10)

In Catherine's account, we can identify two sources of conflict: the dress, as the material was growing thinner and susceptible to being lifted by the wind, and Catherine, outgrowing the dress. Two reasons could have prompted disposal, but this was not the case. Instead, we identified two approaches to conflict: cooperation, as she decides to start wearing shorts to use the dress without worrying that her underwear is exposed, coupled with conscious avoidance of such accidents, representing the compromise of not wearing the dress on windy days.

\subsection{The Role of Forgiveness}

Forgiveness is not usually applied in interpersonal conflict research because it is considered a means to deal with offences, that is, situations that involve personal damage rather than conflict [35]. Nevertheless, "conflicts and offences are especially likely to cooccur in daily life" of close relationships [35] (p. 36) where one type of situation frequently leads to or feeds the other. Moreover, forgiveness is studied outside the scope of conflict strategies because it is an entirely personal phenomenon-in such a situation, unforgiveness takes shape as a negative spiral of avoidant, revengeful, or resentful thoughts, feelings, and behaviours towards the offender, whereas forgiveness is shaped by an "attitude of goodwill" [35], such as Kitty's towards the fading colour of her dress:

\section{Faded color-sucks but it's still got life!-Kitty (37), Neon Fit $n$ Flare Dress (8)}

No wonder that forgiveness is considered a critical factor for the longevity of romantic relationships [37], happiness, and health [38]. Unlike resentment, which fuels further conflict, forgiveness allows for self-regulation, therefore setting "the stage for reconciliation" [37] (p. 557).

Luskin argues that, in interpersonal relationships, "the first element of forgiveness is the ability to be accepting when your spouse fails to give you what you want or imposes on you something you don't want." [38] (p. 14). Similarly, our study suggests that participants accept when clothes fail to provide what they want (e.g., a good look) or imposes something they do not want (e.g., a broken zipper) since these situations are bound to happen. While forgiveness may not mitigate the frustration and disappointment when clashes happen, it may help when those events are unexpected since acceptance requires making peace with such occurrences [38].

So, the ability to forgive plays a significant role in wearer-clothing relationships when an interaction results in a negative experience.

The puller on the front zipper broke. I felt sad for not having it in perfect condition, but it did not significantly change the functionality so I kept wearing the jacket.—Diana (48), Long Padded Jacket (15)

This happens when an individual decides to adjust the relevance of a quality change in an item to make it still fit their love standards [10]. To go on loving an item "depends not only on characteristics of the product but also on people's willingness to adjust and maintain their love." [10] (p. 136): 


\section{Faded but I still love them and wear them.-Clara (39), Red Sweatpants (2)}

Forgiveness implies a willingness to prolong the relationship despite the obstacles [37]. Overcoming negative experiences can benefit the relationship, as "meaningful interactions with products are decision moments in which people contemplate and evaluate their experiences against their standards for love and in which they exercise their generosity towards a product's faults" [10] (p. 143). Note, however, that forgiveness does not necessarily mean compromise, as "one can be forgiving and tolerant without wavering on one's position." [35] (p. 28).

Braithwaite et al. warn about adverse effects of forgiveness, suggesting that forgiving partners may be too passive or excessively avoidant of conflict, which deteriorates relationship satisfaction [37]. Unfortunately, this is difficult to assess in wearer-clothing relationships. For some wearers, acceptance of wear and tear comes with the effort of mending. In contrast, for others it is "symbolic of a personal, individual path, with breakages (mended or raw) as a powerful visualization of our activities, memories of moments, the scars of our everyday, an integral part of our clothes' stories" [11] (p. 16). However, wearers may "accept" wear and tear without acting due to unwillingness or inability to deal with the issue (e.g., lack of time, mending knowledge or tools) and end up rejecting conflict by avoiding using the garment or by accepting the minor flaw and perhaps lowering the expectations on the garment. In the latter case, if the issue is left to escalate (e.g., a small hole that grows), it becomes challenging to take a constructive approach to conflict, thus harming the relationship beyond repair.

\section{Discussion and Implications}

Our findings suggest that wearer-clothing relationships are bound to suffer mishaps and that the willingness and ability of the wearer to deal with conflict is paramount to the relationship's longevity. Furthermore, conflict can lead to pro-relationship strategies [36] and strengthen person-product relationships [20]. Therefore, when dealt with a positive strategy, conflict may contribute to the continuity of the wearer-clothing relationship and not to its deterioration.

Garment-related conflicts were the most frequently reported in our study, highlighting the importance of material endurance to delay that source of conflict. Nevertheless, conflict is likely to happen, be it related to garment, wearer, or context. Most wearer-clothing relationships from our study have endured despite the conflicts originating from changes in garments: while some make efforts to repair (cooperation), others keep wearing the item despite its flaws (compromise, forgiveness) because it is still worth using. Thus, the active lifespan of a garment is extended beyond mishaps because the wearer-clothing relationship developed to the point where going to some lengths to keep using the item seems worthwhile in the eyes of the wearer. From an environmental point of view, efforts should be made to improve the resilience of wearer-clothing relationships, as it seems to have a significant impact on the extended use of garments. Accordingly, efforts should be made to steer wearers away from carelessness and low resistance to conflict, given that the decision to end the relationship is almost always on their side.

We believe this study provides a relevant lens through which one can analyse the impact of new circular business initiatives to promote garment longevity. For example, our findings may make one doubt the benefits of rental business models for everyday clothing. Rental is based on the constant flow of items, which is not compatible with the development of good wearer-clothing relationships. This "no strings attached" option moves in the opposite direction of the willingness of wearers to deal with conflict to extend their relationship with clothing. A recent study on the environmental impact of rental clothing showed that customers kept buying formal dresses despite renting because they wished to have a dress they could wear several times [39]. It is the familiarity of continuous use that nurtures the responsibility and care for the garments we own [6]. Shared ownership tends to decrease this sense of responsibility [40], whereas lack of ownership may cause unease for fear of damaging something one does not own [41]. This detachment from 
material ownership may lead wearers further away from the respect and love "that are a fundamental part of emotional ownership, together with the desire to make things last" [11] (p. 20).

For this reason, clothing items in the rental circuit are unlikely to thrive beyond the pilling and colour fading. While the rental service provider may guarantee the items' maintenance and repair, there is only so much that can be done: items with signs of wear will naturally be removed from circulation, meaning that clothes in the rental circuit may result in fewer wear times before disposal when compared with those in long-term satisfying wearer-clothing relationships. This adds up to other concerns related to rental services, such as the higher potential global warming impacts, compared to extending the use of items already owned [42]. These echo Laitala and Klepp's suggestion to focus on extending the clothing's lifespan with its first user, arguing that "circular economy initiatives should therefore prioritise the use rather than reuse to start with" [28] (p. 4).

In this paper, we highlight how lay beliefs determine part of people's behaviour in the relationships with their clothes (e.g., conflict is a sign of relationship deterioration) and social norms (e.g., disposal of any defective item). These personal expectations shape social expectations, which in turn affect personal behaviour.

Initiatives such as Fletcher's "Local Wisdom" project and the resulting book Craft of Use highlight everyday examples of enjoyable use of clothes and ways of participating in fashion beyond the act of buying [4], which helps reshape these lay beliefs. Equally essential for this transformation are practices of care, such as mending, where people learn to see material goods differently, value them, and keep them in use [32]. Our findings show that garment repair is a positive way for wearers to overcome conflict with their clothes, which makes it a key practice for garment longevity. However, as Vaughan notes, "developing norms of care takes time and must be understood not just through the relationship between the carer and the subject of care, but also through greater sociocultural contexts and expectations." [43] (p. 12).

A 2018 study on Norwegian mending practices showed that a growing number of people are undertaking garment repairs [44]. The personal and social recognition of such activities helps us raise awareness and question the way we deal with imperfection in the material world [32]. To this end, one-way dissemination (e.g., media campaigns, labels) is insufficient to ingrain mending practices [45] and change mindsets towards caring for clothes. König notes that "mending is in fact an activity that is loaded with cultural significance" [32] (p. 570), so it is through cultural and social practices that we can sustain them as "culturally based caring norms" [43].

Fortunately, mending is becoming associated with leisure instead of work [32,44], and the recent revival of mending groups [32] draws awareness to the practice of care for garments already owned. Furthermore, mending advice and repair services offered by brands (e.g., Patagonia [46] and H\&M [47]) may help to promote a caring attitude towards one's clothes, while also supporting the wearer's ability to successfully overcome garment-related conflict. Bringing care from the privacy of the home to the social sphere contributes to a shift towards post-growth fashion [33] and re-shapes lay-beliefs on wearer-clothing relationships.

\section{Conclusions}

People relate to their clothes in a complex way. Therefore, promoting a thrifty use of natural resources in the textile sector becomes particularly challenging. As we explored reasons for garment longevity, we learned that many participants from our study experienced mishaps during the relationship with their clothes that did not result in garment disposal.

The study suggests that wearer-clothing relationships are bound to face adversity at some point in time. Further examination points to the ability to deal with conflict as paramount for the longevity of wearer-clothing relationships. Data analysis under the theoretical framework of interpersonal relationships provides new understandings of how wearers deal with conflict in the relationships with their clothes. This may contribute 
to expanding knowledge on how people relate to material culture and to research on product lifetimes.

Implications include concern over initiatives that damage the wearer's will and ability to withstand conflict with their clothes (e.g., rental business models) and support for activities (e.g., mending) that can benefit the proliferation of caring practices.

Designing well-made, easy-to-care durable garments is an important step towards garment longevity: after all, wearers can only enjoy their clothes for longer if these are made to last. However, this paper draws attention to the reality of conflict in wearerclothing relationships, which are unavoidable regardless of garment quality. Therefore, designers and brands should also focus their attention on users, namely on the motivations, skills, and stimulus that drive care for their products [40]. Moreover, and because conflict can also originate from context or the wearers themselves, further research should seek to understand if and how the will and ability of wearers to deal with conflict can be encouraged and nurtured and what role design can have in that task.

Author Contributions: Conceptualization, A.N. and J.F.; methodology, A.N. and J.F; investigation, A.N.; formal analysis, A.N.; data curation, A.N.; writing—original draft preparation, A.N.; writingreview and editing, A.N. and J.F.; supervision, J.F. All authors have read and agreed to the published version of the manuscript.

Funding: This work is supported by national funds through FCT-Fundação para a Ciência e a Tecnologia, I.P., under the Strategic Project with the reference UIDB/04008/2020, and the doctoral grant with the reference 2021.04933.BD.

Institutional Review Board Statement: Not Applicable.

Informed Consent Statement: Informed consent was obtained from all subjects involved in the study.

Data Availability Statement: The data presented in this study are available on reasonable request from the corresponding author.

Acknowledgments: This paper is a revised and expanded version of the conference paper titled "Through Thick and Thin: Committing to a long-lasting wearing-clothing relationship" presented at the Product Lifetimes and the Environment (PLATE) 2021 Conference. We would like to thank Pedro Ramos for proofreading and language editing the manuscript, and the anonymous reviewers whose critiques and comments improved this paper and contributed to future stages of our research project. Thank you also to Naomi Ruth and Mafalda Casais for the enlightening conversations and invaluable suggestions.

Conflicts of Interest: The authors declare no conflict of interest. The funders had no role in the design of the study; in the collection, analyses, or interpretation of data; in the writing of the manuscript, or in the decision to publish the results.

\section{Appendix A}

Survey Questions:

1. Year of Birth:

2. Gender: $\square M \square F \square$ Other

3. Nationality:

4. Country of Residence:

5. Studies:

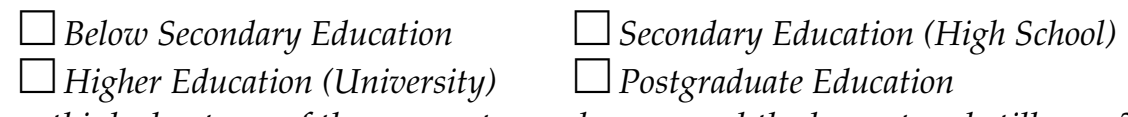

6. Can you think about one of the garments you have owned the longest and still wear? Please describe it.

7. Is it a favourite item? $\square$ Yes $\square$ No

8. Since when have you owned it? (can you tell the year and the season or the month?)

9. Can you describe the qualities (physical or not), that has made it last for so long in your life?

10. How did it enter your life? 


\section{Bought it}

Where? (for example: brand online/physical shop; a market; second-hand)

What were the most important qualities you were looking for in that type of garment?

Did that specific garment have those qualities?

$\square$ Received it

From whom? Did you choose it? Was it a surprise? What did you think of it at first?

$\square$ Can't remember

11. Did you always use it with the same frequency?

$\square$ Yes

How frequently (approximate times per month)?

$\square$ No

What happened? Can you recall what made you wear it more and less frequently through time?

12. How do you usually take care of it (routine care; when it gets damaged; when out of season; or other)?

13. Can you recall a special moment you had with it? What happened? How did you feel?

What did you feel about the garment, if anything?

14. Can you recall a negative moment you had with it? What happened? How did you feel?

What did you feel about the garment, if anything?

15. Has the garment ever suffered any damage? (e.g., stubborn stain; ripped seam, hole, broken zipper or lost button; colour change ... )

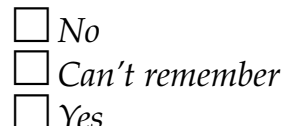

What was it? How did you feel about it when it happened?

What did you do?

$\square$ I repaired it

$\square$ I asked or paid someone to repair it

$\square$ I decided to keep wearing it anyway

16. Right now, what are the most important qualities you are looking for in that type of garment? Does that specific garment have those qualities?

17. How would you rate your relationship with that garment now?

(5-point scale, in which 1 = "very unhappy" and $5=$ "very happy")

\section{References}

1. Laitala, K.; Boks, C. Sustainable clothing design: Use matters. J. Des. Res. 2012, 10, 121-139. [CrossRef]

2. Niinimäki, K.; Peters, G.; Dahlbo, H.; Perry, P.; Rissanen, T.; Gwilt, A. The Environmental Price of Fast Fashion. Nat. Rev. Earth Environ. 2020, 1, 189-200. [CrossRef]

3. Cooper, T.; Hill, H.; Kininmonth, J.; Townsend, K.; Hughes, M.; Shorrocks, J.; Knox, A.; Fisher, T.; Saicheua, V. Design for Longevity —Guidance on Increasing the Active Life of Clothing; Wrap: Banbury, UK, 2013. Available online: https:/ /wrap.org.uk/ sites/default/files/2020-10/WRAP-Design\%20for\%20Longevity\%20Report_0.pdf (accessed on 8 November 2021).

4. Fletcher, K. Craft of Use: Post-Growth Fashion; Routledge: Abingdon, UK, 2016.

5. Woodward, S. Why Women Wear What They Wear; Berg: Oxford, UK; New York, NY, USA, 2007.

6. Burcikova, M. Mudane Fashion: Women, Clothes and Emotional Durability. Ph.D. Thesis, School of Art, Design and Architecture, University of Huddersfield, Huddersfield, UK, 2019.

7. Niinimäki, K.; Armstrong, C. From pleasure in use to preservation of meaningful memories: A closer look at the sustainability of clothing via longevity and attachment. Int. J. Fash. Des. Technol. Educ. 2013, 6, 190-199. [CrossRef]

8. McIntyre, M.P. Shame, Blame, and Passion: Affects of (Un)sustainable Wardrobes. Fash. Theory J. Dressbody Cult. 2021, 25, 735-755. [CrossRef]

9. Chapman, J. Emotionally Durable Design: Objects, Experiences and Empathy, 2nd ed.; Routledge: Abingdon, UK; New York, NY, USA, 2015.

10. Russo, B. Shoes, Cars and Other Love Stories: Investigating the Experience of Love for Products. Ph.D. Thesis, Delft University of Technology, Delft, The Netherlands, 2010.

11. Castro, O. Loved Clothes Last: How the Joy of Rewearing and Repairing Your Clothes Can Be a Revolutionary Act; Penguin Life: London, $\mathrm{UK}, 2021$. 
12. Levinger, G. Toward the analysis of close relationships. J. Exp. Social Psychol. 1980, 16, 510-544. [CrossRef]

13. Gregson, N.; Metcalfe, A.; Crewe, L. Moving things along: The conduits and practices of divestment in consumption. Trans. Inst. Br. Geographers. 2007, 32, 187-200. [CrossRef]

14. Encino-Muñoz, A.G.; Sumner, M.; Sinha, P.; Carnie, B. Towards a taxonomy of divestment. The lifespan of products as a process. In Proceedings of the Plate Product Lifetimes and the Environment Conference, Virtual Conference, Limerick, Ireland, 26-28 May 2021; University of Limerick: Limerick, Ireland, 2021.

15. Muratovski, G. Research for Designers: A Guide to Methods and Practice; Sage: Los Angeles, CA, USA, 2016.

16. Braun, V.; Clarke, V.; Boulton, E.; Davey, L.; McEvoy, C. The online survey as a qualitative research tool. Int. J. Soc. Res. Methodol. 2020, 24, 641-654. [CrossRef]

17. Glaser, B.; Strauss, A. The Discovery of Grounded Theory: Strategies for Qualitative Research; Transaction Publishers: London, UK, 2006.

18. Zacchilli, T.L.; Hendrick, C.; Hendrik, S.S. The romantic partner conflict scale: A new scale to measure relationship conflict. J. Soc. Pers. Relatsh. 2009, 26, 1073-1096. [CrossRef]

19. Gottman, J.; Gottman, J. The natural principles of love. J. Fam. Theory Rev. 2017, 9, 7-26. [CrossRef]

20. Valle-Noronha, J.; Niinimäki, K.; Kujala, S. Notes on wearer-worn attachments: Learning to wear. Cloth. Cult. 2018, 5, 225-246. [CrossRef]

21. Duck, S. Human Relationships, 4th ed.; SAGE: London, UK, 2007.

22. Meunier, V.; Baker, W. Positive Couple Relationships: The Evidence for Long-Lasting Relationship Satisfaction and Happiness. In Positive Relationships; Roffey, S., Ed.; Springer: Dordrecht, The Netherlands, 2012; pp. 73-89. [CrossRef]

23. Alford-Cooper, F. For Keeps: Marriages That Last a Lifetime; ME Sharpe, Inc.: Armonk, NY, USA, 1998.

24. Mugge, R. Product Attachment. Ph.D. Thesis, Delft University of Technology, Delft, The Netherlands, 2007.

25. Degenstein, L.M.; McQueen, R.H.; McNeill, L.S.; Hamlin, R.P.; Wakes, S.J.; Dunn, L.A. Impact of physical condition on disposal and end-of-life extension of clothing. Int. J. Consum. Stud. 2020, 44, 586-596. [CrossRef]

26. Guy, A.; Banim, M. Personal Collections: Women's clothing use and identity. J. Gend. Stud. 2000, 9, 313-327. [CrossRef]

27. Bye, E.; McKinney, E. Sizing up the Wardrobe-Why We Keep Clothes That Do Not Fit. Fash. Theory 2007, 11, 483-498. [CrossRef]

28. Laitala, K.; Klepp, I.G. Clothing Longevity: The Relationship Between the Number of Users, How Long and How Many Times Garments are Used. In Proceedings of the Plate Product Lifetimes and the Environment Conference, Virtual Conference, Limerick, Ireland, 26-28 May 2021; University of Limerick: Limerick, Ireland, 2021. [CrossRef]

29. Klepp, I.G.; Laitala, K.; Haugrønning, V. Wardrobe sizes and clothing lifespans. In Proceedings of the Plate Product Lifetimes and the Environment Conference, Berlin, Germany, 18-20 September 2019; Nissen, N.F., Jaeger-Erben, M., Eds.; Universitätsverlag der TU Berlin: Berlin, Germany, 2021; pp. 451-456.

30. Busch, O. Inclusive Fashion-An Oxymoron-Or a Possibility for Sustainable Fashion? Fash. Pract. 2018, 10, 311-327. [CrossRef]

31. Zagefka, H.; Bahul, K. Beliefs That Contribute to Dissatisfaction in Romantic Relationships. Fam. J. Couns. Ther. Couples Fam. 2020, 29, 153-160. [CrossRef]

32. König, A. A stitch in time: Changing cultural constructions of craft and mending. Cult. Unbound J. Curr. Cult. Res. 2013, 5, 569-585. [CrossRef]

33. Middleton, J. Mending. In Routledge Handbook of Sustainability and Fashion; Fletcher, K., Tham, M., Eds.; Routledge: Abingdon, UK; New York, NY, USA, 2015; pp. 262-274.

34. Canary, D.J.; Cupach, W.R. Relational and Episodic Characteristics Associated with Conflict Tactics. J. Soc. Pers. Relatsh. 1988, 5, 305-325. [CrossRef]

35. Paleari, F.G.; Regalia, C.; Fincham, F.D. Forgiveness and conflict resolution in close relationships: Within and cross partner effects. Univ. Psychol. 2010, 9, 35-56. [CrossRef]

36. Kayabol, N.B.A.; Gonzalez, J.-M.; Gamble, H.; Totenhagen, C.J.; Curran, M.A. Levels and volatility in daily relationship quality: Roles of daily sacrifice motives. J. Soc. Pers. Relatsh. 2020, 37, 2967-2986. [CrossRef]

37. Braithwaite, S.R.; Selby, E.A.; Fincham, F.D. Forgiveness and relationship satisfaction: Mediating mechanisms. J. Fam. Psychol. 2011, 25, 551-559. [CrossRef] [PubMed]

38. Luskin, F. Forgive for Love: The Missing Ingredient for a Healthy and Lasting Relationship; HarperCollins: New York, NY, USA, 2007.

39. Johnson, E.; Plepys, A. Product-Service Systems and Sustainability: Analysing the Environmental Impacts of Rental Clothing. Sustainability 2021, 13, 2118. [CrossRef]

40. Ackermann, L.; Mugge, R.; Schoormans, J. Consumers' Perspective on Product Care: An Exploratory Study of Motivators, Ability Factors, and Triggers. J. Clean. Prod. 2018, 183, 380-391. [CrossRef]

41. Cherry, C.E.; Pidgeon, N.F. Why Is Ownership an Issue? Exploring Factors That Determine Public Acceptance of Product-Service Systems. Sustainability 2018, 10, 2289. [CrossRef]

42. Levänen, J.; Uusitalo, V.; Härri, A.; Kareinen, E.; Linnanen, L. Innovative recycling or extended use? Comparing the global warming potential of different ownership and end-of-life scenarios for textiles. Environ. Res. Lett. 2021, 16, 054069. [CrossRef]

43. Vaughan, L. Design as a Practice of Care. In Designing Cultures of Care; Vaughan, L., Ed.; Bloomsbury Publishing: London, UK, 2018; pp. 7-17. [CrossRef]

44. Laitala, K.; Klepp, I.G. Care and Production of Clothing in Norwegian Homes: Environmental Implications of Mending and Making Practices. Sustainability 2018, 10, 2899. [CrossRef] 
45. Durrani, M. “People Gather for Stranger Things, So Why Not This?" Learning Sustainable Sensibilities through Communal Garment-Mending Practices. Sustainability 2018, 10, 2218. [CrossRef]

46. Patagonia. Repair Process. Available online: https://help.patagonia.com/s/article/Repair-Process (accessed on 8 November 2021).

47. H\&M Group. Shifting to a Circular Future through Resell, Repair and Rental. Available online: https://hmgroup.com/ourstories/shifting-to-a-circular-future-through-resell-repair-and-rental/ (accessed on 8 November 2021). 